\title{
Pengendali Suhu, Kelembaban dan Cahaya Berbasis Arduino dan IOT pada Kumbung Jamur Tiram
}

\author{
Muhammad Akbar Setiawan', Sunaryono \\ akbar@swu.ac.id ${ }^{1}$, sunaryono@swu.ac.id $^{2}$ \\ S1 Teknik Informatika STMIK Widya Utama \\ Jl.Sunan Kalijaga Berkoh
}

\begin{abstract}
Abstrak
Jamur tiram adalah jamur pangan yang memiliki morfologi dengan tudung mirip cangkang tiram dengan bagian tengah agak cekung dan berwarna putih hingga krem. Syarat yang penting agar jamur dapat tumbuh maksimal adalah dengan menjaga suhu, kelembabannya serta intensitas cahaya ketika akan tumbuh buah. Untuk jamur tiram syarat untuk suhu dan kelembaban yang harus terpenuhi agar jamur dapat tumbuh optimal ialah suhu $20-30{ }^{\circ} \mathrm{C}$, kelembaban minimal $80 \%$ dan intensitas cahaya pada saat tumbuh buah adalah sekitar 200 lux. Salah satu kelemahan dalam pembudidayaan jamur tiram adalah tidak diketahuinya suhu, kelembaban serta intensitas cahaya dalam kumbung tanpa alat bantu pengukuran. Alat bantu pengukuran ini hanya akan mengukur seberapa besar suhu, kelembaban ruangan, pengendalian suhu, dan kelembaban ruangan tetap manual dalam penjagaanya. Kelemahan tersebut coba diatasi oleh peneliti dengan membangun sebuah alat pengendali suhu dan kelembaban yang berbasis Arduino. Alat pengendali suhu dan kelembaban ini dibangun untuk memudahkan petani dalam menjaga suhu dan kelembaban di dalam kumbung jamur tiram. Fungsi dari alat ini akan memberi pelayanan berupa pengiriman data suhu dan kelembaban secara waktu nyata ke Aplikasi Smartphone Blynk serta mampu memberikan output menjaga suhu dan kelembaban dengan cara memutar kipas untuk mendinginkan suhu dan menyemprotkan air untuk menambah kelembaban relatif, sehingga tercapai suhu dan kelembaban ideal untuk pertumbuhan Jamur Tiram. Dari hasil penelitian ini menunjukkan bahwa Sistem yang dibangun dapat mencapai hasil yang diharapkan yaitu mampu memberikan rekayasa pengendalian suhu, kelembaban dan intensitas cahaya didalam kumbung jamur tiram.
\end{abstract}

Kata kunci : jamur tiram, arduino, sensor suhu, Internet of Things

\section{Pendahuluan}

Trend berwirausaha saat ini sedang mengalami peningkatan yang pesat, salah satu bidang yang berkembang ialah bidang budidaya jamur konsumsi. Jenis jamur konsumsi yang biasa dibudidayakan di Indonesia ada 3 jenis yaitu Jamur Merang, Jamur Tiram, dan Jamur Kuping [1].

Tanaman jamur tiram ini memiliki berbagai persyaratan untuk tumbuh secara optimal, dan salah satu syarat yang paling penting ialah pengaturan suhu dan kelembaban kumbung atau rumah jamur tiram (selanjutnya disebut kumbung saja). Agar dapat tumbuh optimal, ruangan dalam kumbung harus memiliki suhu antara $20-30^{\circ} \mathrm{C}$ dan kelembaban minimal $80 \%$ [1].

Pengkondisian suhu dan kelembaban dalam kumbung selama ini masih menggunakan cara - cara yang sederhana seperti yang telah disebutkan di atas, namun dengan melakukan cara - cara tersebut juga masih belum bisa diketahui secara pasti berapa suhu dan kelembaban karena ketiadaan alat ukur suhu dan kelembaban. Pengukuran suhu dan kelembaban menjadi hal yang sangat diperlukan untuk menjaga kondisi yang ideal terjaganya suhu dan kelembaban di dalam kumbung jamur.

Permukaan tudung jamur tiram licin, agak berminyak saat lembap, dan tepianya bergelombang. Diameternya $3-20 \mathrm{~cm}$ [1]. Syarat yang penting agar jamur dapat tumbuh maksimal adalah dengan menjaga suhu dan kelmbabannya. Untuk jamur tiram syarat untuk suhu dan kelmbaban yang harus terpenuhi agar jamur dapat tumbuh optimal ialah suhu $20-30{ }^{\circ} \mathrm{C}$ dan kelembaban minimal 80\% [2] .

Pengertian secara fisika, suhu menunjukan derajat panas suatu benda. Secara mikroskopis, suhu menunjukkan energi yang dimiliki oleh suatu benda. Setiap atom dalam suatu benda masing-masing bergerak, baik itu dalam bentuk perpindahan maupun gerakan di tempat 
berupa getaran. Makin tingginya energi atom-atom penyusun benda, makin tinggi suhu benda tersebut [3]. Sedangkan kelembaban relatif (Relative Humidity) didefinisikan sebagai rasio dari tekanan parsial uap air dalam campuran terhadap tekanan uap jenuh air pada temperatur tersebut [4]. .

Disebabkan begitu pentingnya menjaga kestabilan suhu dan kelambaban dalam kumbung, maka penulis berinisiatif untuk membangun sebuah alat pengendali yang mampu menjaga kestabilan suhu, kelembaban, dan cahaya dalam kumbung jamur berbasis Arduino. Pengendalian ini diatur oleh sebuah modul Arduino Uno. Arduino Uno adalah sebuah board yang menggunakan mikrokontroler ATmega328. Arduino Uno memiliki 14 pin digital (6 pin dapat digunakan sebagai output PWM), 6 input analog, sebuah 16 $\mathrm{MHz}$ osilato kristal, sebuah koneksi USB, sebuah konektor sumber tegangan, sebuah header ICSP, dan sebuah tombol reset.

Tampak atas dari arduino uno dapat dilihat pada Gambar 1:

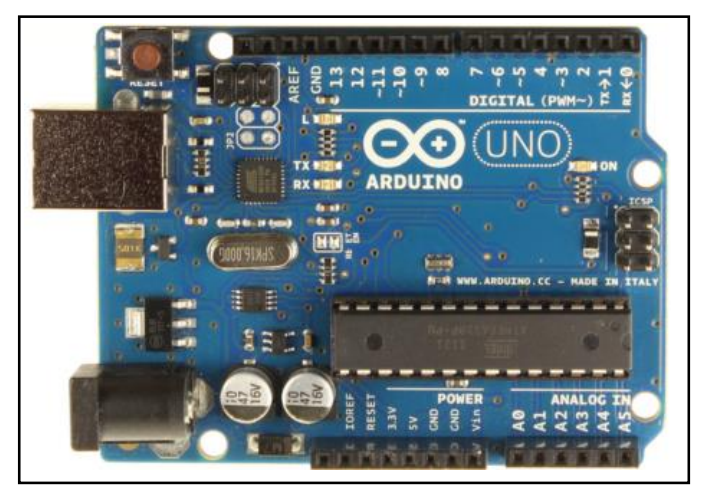

Gambar 1. Arduino Uno

Sumber (geeetech.com)

Pembangunan alat pengendali suhu dan kelembaban di rumah jamur ini pula tak terlepas dari fungsi - fungsi sensor suhu, kelembaban dan cahaya untuk menentukan masukkan ( Input ). Sensor atau transducer adalah salah satu elemen penting dalam system instrumentasi dan pengendali, transducer akan mengubah energy nonlistrik menjadi energy listrik sehingga proses pengendalian dapat dilakukan baik secara otomatik atau manual [5] . Menurut klasifikasinya, sensor suhu dan kelembaban termasuk dalam jenis transducer pasif, yang artinya ia tidak dapat menghasilkan tegangan sendiri tetapi dapat menghasilkan perubahan nilai resistansi, kapasitansi atau induktansi apabila mengalami perubahan kondisi sekeliling [5].

Sensor suhu dan kelembaban merupakan sensor yang akan mengalami perubahan resistansi apabila dikenai rangsangan berupa suhu dan atau kelembaban. Namun juga terdapat sensor suhu yang tergolong transducer aktif, yaitu jenis transducer Thermokopel dan Thermopile [5]. Penulis disini akan membangun sebuah alat menggunakan sensor suhu dan kelembaban berjenis SHT 11, yang memiliki dua jenis sensor yaitu sensor suhu dan kelembaban yang keluaranya merupakan data digital [6] (A.sofwan, 2005), output dari sensor inilah yang akan menjadi input untuk kemudain diolah dalam mikrokontroler ATmega8535 yang telah diisi dengan muatan logika berbahasa BASIC.

DT-SENSE SHT11 Module merupakan modul sensor suhu dan kelembaban relatif yang berbasis sensor SHT11 dari Sensirion. Modul ini dapat digunakan sebagai alat pengindra suhu dan atau kelembaban dalam aplikasi pengendali suhu dan atau kelembaban ruangan maupun aplikasi pemantau suhu dan atau kelembaban relative ruangan [6].

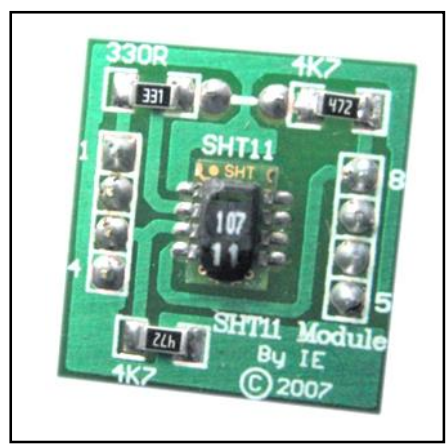

Gambar 2. Modul DT sense SHT11 Sumber [7] ( www.tokopedia.com)

Dalam rangkaian elektronika juga digunakan komponen - komponen yang mendukungnya seperti contohnya transistor, resistor, kapasitor dan dioda. Transistor menurut asal katanya yaitu Transfer Resistor yang berarti nilai resistansi antar terminalnya dapat diatur [8] . Pengembangan alat pengendali suhu 
dan kelembaban di rumah jamur ini menggunakan metode prototype, dengan metode prototyping ini pengembang dan pelanggan dapat saling berinteraksi selama proses pembuatan sistem. Untuk mengatasi ketidakserasian antara pelanggan dan pengembang, maka harus dibutuhakan kerjasama yang baik diantara keduanya sehingga pengembang akan mengetahui dengan benar apa yang diinginkan pelanggan dengan tidak mengesampingkan segi-segi teknis dan pelanggan akan mengetahui proses-proses dalam menyelasaikan system yang diinginkan [9]

\section{Metode Penelitian}

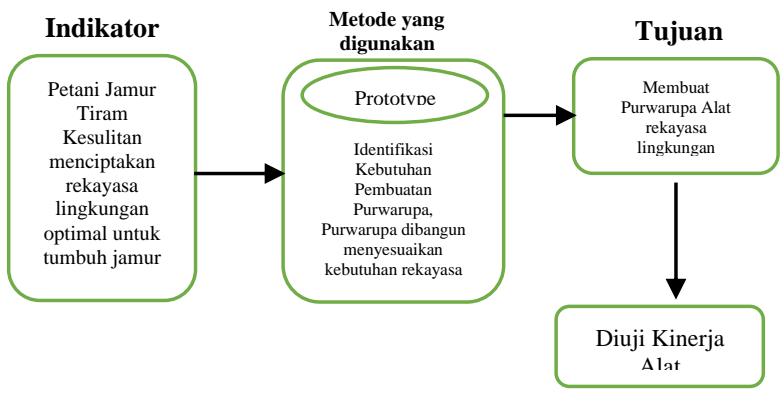

Kebutuhan untuk Pembangunan Purwarupa Alat Pengendali Suhu Kelmbaban dan Cahaya Di kumbung Jamur Tiram :

Hardware yang digunakan antara lain :

a. Modul Arduino Uno

b. Modul WiFi

c. Sensor suhu dan kelembaban DTsense SHT 11

d. Sensor Cahaya

e. Transistor

f. Resistor

g. Dioda

h. Kapasitor

i. Kipas

j. Sistem penyemprot air ( menggunakan pompa akuarium untuk modelnya )

k. Purwarupa Kumbung Jamur dengan Akrilik

Software yang digunakan ialah bahasa $\mathrm{C}++$ Arduino IDE untuk Pembuatan Program Arduino dan Blynk untuk pembangunan Software IoT.

Tahap berikutnya ialah desain cara kerja sistem secara umum dengan menggunakan Diagram alir .

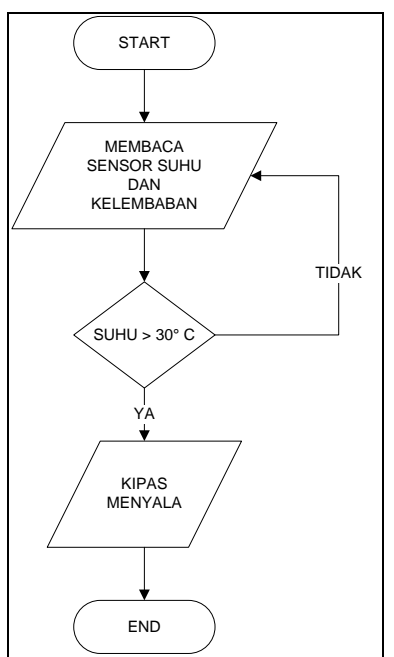

Gambar 3. Diagram Alir Pembacaan Suhu

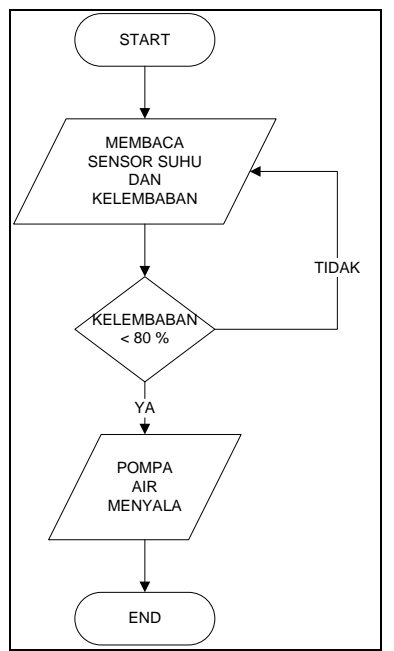

Gambar 4. Diagram Alir Pembacaan Kelembaban

Setelah membuat gambaran umum cara kerja melalui Diagram alir, selanjutnya membuat desain interface untuk rekayasa hardware pengendali suhu dan kelembaban. Tahapan ini dilakukan oleh ketua peneliti, termasuk juga ketika pembuatan Program yang akan dibenamkan ke dalam arduino.

Dalam tahap ini juga dibuat gambaran mengenai rangkaian elektronika yang digunakan dalam alat pengendali suhu dan kelembaban di rumah jamur, seperti pada gambar berikut: 


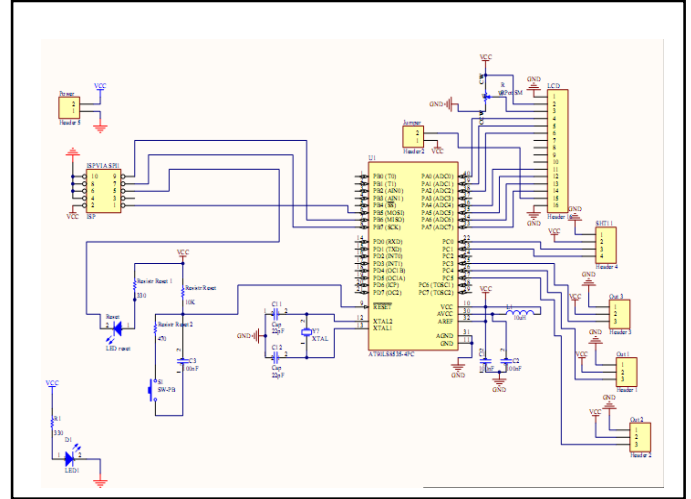

Gambar 5. Rangkaian Sistem secara garis besar

Perancangan selanjutnya adalah perancangan pembuatan aplikasi android Blynk sebagai implementasi teknologi IoT, yang mana website dan atau aplikasi android ini nantinya akan menampilkan data suhu, kelembaban dan intensitas cahaya secara waktu nyata kepada user.

\section{Hasil dan Pembahasan}

Hasil pengembangan system dengan metode prototype adalah sebuah alat pengendali Suhu, kelembaban dan cahaya dirumah jamur tiram, dengan kinerja sebagai berikut :

a. Alat dapat dioperasikan dengan mudah

b. Alat yang dibangun dapat mendeteksi Suhu, kelembaban dan cahaya sesuai dengan yang dibutuhkan sebagai syarat optimal tumbuhnya jamur

c. Mikrokontroler dapat mengeluarkan output berupa perintah yang akan memerintahkan saklar (Relay) untuk menyala atau mati.

d. Alat yang dibangun mampu digunakan tanpa kesalahan.

e. Program dalam mikrokontroler mampu bekerja sesuai dengan yang diharapkan, yaitu mampu membaca keluaran dari sensor, dan memberi perintah kepada saklar (relay) kipas dan atau (relay) penyemprot air serta Lampu LED untuk bekerja jika Suhu, kelembaban dan cahaya tidak sesuai dengan syarat optimal tumbuhnya jamur.

f. Alat yang dibangun mampu memenuhi spesifikasi yaitu :

1. Kelembaban rumah jamur dijaga agar diatas $80 \%$.

2. Suhu berkisar antara $20-30{ }^{\circ} \mathrm{C}$.
3. Sensor yang digunakan merupakan sensor Suhu dan kelembaban dan sensor cahaya.

4. Luas rumah jamur menggunakan purwarupa rumah jamur berukuran panjang, lebar dan tinggi $40 \mathrm{~cm} \mathrm{X}$ $40 \mathrm{~cm} \mathrm{X} 40 \mathrm{~cm}$. purwarupa ini menggunakan bahan dasar Acrilyc.

Setelah menentukan kinerja yang diukur kemudian peneliti melakukan pengujian. Pengujian dan alisis sistem dalam penelitian ini secacra umum terbagi kedalam dua hal, yaitu:

a. Pengujian dan analisis perangkat keras yang meliputi pengujian dan analisis rangkaian Arduino Uno dan Modul Wifi ESP8266, serta Sensor Suhu dan Kelembaban dan Sensor Cahaya, yang tersambung dengan relay dc 4 channel yang dihubungkan dengan alat output penurun suhu berupa kipas, penambah kelembaban berupa Semprotan Kabut air, dan penambah intensitas cahaya berupa lampu LED.

b. Pengujian dan analisis perangkat lunak yang diimplementasikan menggunakan program Blynk, yang digunakan sebagai pengendali dan pemantau kendaraan Dalam pengujian perangkat lunak ini menggunakan metode pengujian black box. Pengujian black box adalah pengujian aspek fundamental sistem tanpa memperhatikan stuktur logika internal perangkat lunak. Metode ini digunakan untuk mengetahui apakah perangkat lunak berfungsi dengan benar.

Tabel 6. Item Pengujian Perangkat Keras

\begin{tabular}{llll}
\hline $\begin{array}{l}\text { Alat Yang } \\
\text { Diuji }\end{array}$ & $\begin{array}{l}\text { Butir } \\
\text { Pengujian }\end{array}$ & $\begin{array}{l}\text { Jumlah } \\
\text { Uji }\end{array}$ & $\begin{array}{l}\text { Hasil } \\
\text { Pengujian }\end{array}$ \\
\hline $\begin{array}{l}\text { Modul Wifi } \\
\text { ESP8266 }\end{array}$ & $\begin{array}{l}\text { Pengiriman } \\
\text { Data Ke } \\
\text { Perangkat } \\
\text { Client Blynk }\end{array}$ & 10 Kali & Berhasil \\
& & \\
\hline $\begin{array}{l}\text { Sensor Suhu } \\
\text { dan }\end{array}$ & $\begin{array}{l}\text { Pengujian } \\
\text { Kembacaan }\end{array}$ & 10 Kali & Berhasil \\
& & \\
\hline
\end{tabular}




\begin{tabular}{|c|c|c|c|}
\hline & $\begin{array}{l}\text { Pengujian } \\
\text { Pembacaan } \\
\text { kelembaban < } \\
80 \%\end{array}$ & 10 Kali & Berhasil \\
\hline $\begin{array}{l}\text { Sensor } \\
\text { Cahaya }\end{array}$ & $\begin{array}{l}\text { Pengujian } \\
\text { Pembacaan } \\
\text { Intensitas } \\
\text { Cahaya }\end{array}$ & 10 Kali & Berhasil \\
\hline $\begin{array}{l}\text { Relay } 4 \\
\text { Channel }\end{array}$ & $\begin{array}{l}\text { Mengeluarkan } \\
\text { sinyal output } \\
\text { dari perangkat } \\
\text { arduino ke } \\
\text { perangkat } \\
\text { output }\end{array}$ & $10 \mathrm{Kali}$ & Berhasil \\
\hline
\end{tabular}

\begin{tabular}{|c|c|c|c|}
\hline $\begin{array}{l}\text { Switch } \\
\text { Button } \\
\text { Semprot } \\
\text { Kabut }\end{array}$ & $\begin{array}{l}\text { Tombol aktif } \\
\text { dan dapat } \\
\text { Memberi } \\
\text { perintah } \\
\text { kepada alat } \\
\text { keluaran } \\
\text { Semprotan } \\
\text { Kabut jika } \\
\text { kelembaban < } \\
80 \%\end{array}$ & 10 Kali & $\begin{array}{l}\text { Berhasil } 9 \\
\text { Kali } \\
\text { Percobaan }\end{array}$ \\
\hline $\begin{array}{l}\text { Switch } \\
\text { Button } \\
\text { Nyalakan } \\
\text { Lampu }\end{array}$ & $\begin{array}{l}\text { Tombol aktif } \\
\text { dan dapat } \\
\text { Memberi } \\
\text { perintah } \\
\text { kepada alat } \\
\text { keluaran } \\
\text { Lampu LED } \\
\text { untuk menjaga } \\
\text { intensitas } \\
\text { cahaya } 200 \text { lux }\end{array}$ & 10 Kali & $\begin{array}{l}\text { Berhasil } 9 \\
\text { Kali } \\
\text { Percobaan }\end{array}$ \\
\hline $\begin{array}{l}\text { Switch } \\
\text { Button } \\
\text { Nyalakan } \\
\text { Kipas }\end{array}$ & $\begin{array}{l}\text { Tombol tidak } \\
\text { aktif jika Suhu } \\
<=30^{\circ} \mathrm{C} \\
\text { karena sesuai } \\
\text { di lingkungan } \\
\text { ideal tumbuh } \\
\text { kembang jamur } \\
\text { tiram }\end{array}$ & 10 Kali & $\begin{array}{l}\text { Berhasil } 9 \\
\text { Kali } \\
\text { Percobaan }\end{array}$ \\
\hline $\begin{array}{l}\text { Switch } \\
\text { Button } \\
\text { Semprot } \\
\text { Kabut }\end{array}$ & $\begin{array}{l}\text { Tombol tidak } \\
\text { aktif jika } \\
\text { kelembaban > } \\
80 \% \text { karena } \\
\text { sesuai di } \\
\text { lingkungan } \\
\text { ideal tumbuh } \\
\text { kembang jamur } \\
\text { tiram }\end{array}$ & 10 Kali & $\begin{array}{l}\text { Berhasil } 9 \\
\text { Kali } \\
\text { Percobaan }\end{array}$ \\
\hline $\begin{array}{l}\text { Switch } \\
\text { Button } \\
\text { Nyalakan } \\
\text { Lampu }\end{array}$ & $\begin{array}{l}\text { Tombol tidak } \\
\text { aktif jika } \\
\text { intensitas } \\
\text { cahaya } 200 \text { lux }\end{array}$ & $10 \mathrm{Kali}$ & $\begin{array}{l}\text { Berhasil 9 } \\
\text { Kali } \\
\text { Percobaan }\end{array}$ \\
\hline
\end{tabular}

Tabel 7. Item Pengujian Perangkat Lunak

\begin{tabular}{|c|c|c|c|}
\hline $\begin{array}{l}\text { Alat Yang } \\
\text { Diuji }\end{array}$ & $\begin{array}{l}\text { Butir } \\
\text { Pengujian }\end{array}$ & $\begin{array}{l}\text { Jumlah } \\
\text { Uji }\end{array}$ & $\begin{array}{l}\text { Hasil } \\
\text { Pengujian }\end{array}$ \\
\hline $\begin{array}{l}\text { Koneksi } \\
\text { Alat dan } \\
\text { Server } \\
\text { Blynk }\end{array}$ & $\begin{array}{l}\text { Pengiriman } \\
\text { Data Ke } \\
\text { Perangkat } \\
\text { Client Blynk }\end{array}$ & 10 Kali & $\begin{array}{l}\text { Berhasil } 9 \\
\text { Kali } \\
\text { Percobaan }\end{array}$ \\
\hline $\begin{array}{l}\text { Label Value } \\
\text { Suhu }\end{array}$ & $\begin{array}{l}\text { Dapat } \\
\text { Menampilkan } \\
\text { pembacaan } \\
\text { suhu secara } \\
\text { waktu nyata }\end{array}$ & $10 \mathrm{Kali}$ & $\begin{array}{l}\text { Berhasil } 9 \\
\text { Kali } \\
\text { Percobaan }\end{array}$ \\
\hline $\begin{array}{l}\text { Label Value } \\
\text { Kelembaban }\end{array}$ & $\begin{array}{l}\text { Dapat } \\
\text { Menampilkan } \\
\text { pembacaan } \\
\text { kelembaban } \\
\text { secara waktu } \\
\text { nyata }\end{array}$ & $10 \mathrm{Kali}$ & $\begin{array}{l}\text { Berhasil } 9 \\
\text { Kali } \\
\text { Percobaan }\end{array}$ \\
\hline $\begin{array}{l}\text { Label Value } \\
\text { Cahaya }\end{array}$ & $\begin{array}{l}\text { Dapat } \\
\text { Menampilkan } \\
\text { pembacaan } \\
\text { intensitas } \\
\text { cahaya secara } \\
\text { waktu nyata }\end{array}$ & 10 Kali & $\begin{array}{l}\text { Berhasil } 9 \\
\text { Kali } \\
\text { Percobaan }\end{array}$ \\
\hline $\begin{array}{l}\text { Switch } \\
\text { Button } \\
\text { Nyalakan } \\
\text { Kipas }\end{array}$ & $\begin{array}{l}\text { Tombol aktif } \\
\text { dan dapat } \\
\text { Memberi } \\
\text { perintah } \\
\text { kepada alat } \\
\text { keluaran kipas } \\
\text { jika Suhu }>30^{\circ} \\
\text { C }\end{array}$ & 10 Kali & $\begin{array}{l}\text { Berhasil } 9 \\
\text { Kali } \\
\text { Percobaan }\end{array}$ \\
\hline
\end{tabular}

\section{Kesimpulan}

Berdasarkan analisis pembahasan yang dilakukan pada bab sebelumnya dapat diambil kesimpulan antara lain :
a. Alat pengendali suhu, kelembaban dan cahaya ini dapat mengirimkan data suhu kelembaban dan intensitas cahaya ke server Blynk
b. Aplikasi Client Blynk dapat menampilkan data suhu, kelembaban dan cahaya ini dapat mengirimkan 
data suhu kelembaban dan intensitas cahaya.

c. Komunikasi Aplikasi dan Perangkat Keras dapat Melakukan Pengendalian Suhu, Kelmbaban dan Intensitas Cahaya di dalam Purwarupa Kumbung Jamur

\section{Daftar Pustaka}

[1]. Agustini, Verena dkk. 2018. Budidaya Jamur Tiram Putih (Pleurotus Ostreatus) Sebagai Percontohan Dan Unit Usaha Budidaya Jamur (Uubj) di Universitas Cenderawasih. J. Pengabdian Masyarakat MIPA dan Pendidikan MIPA UNY, 2018 Vol 2.

[2]. Karsid dkk. 2015. Aplikasi Kontrol Otomatis Suhu dan Kelembaban untuk Peningkatan Produktivitas Budidaya Jamur Merang. Jurnal Aplikasi Teknologi Pangan(3), 86 - 88.

[3]. Anonim, 2015 http://id.wikipedia.org/wiki/Suhu diakses 17 Juni 2019

[4]. Anonim, 2015 http://id.wikipedia.org/wiki/Kelembab an_relatif diakses 17 Juni 2019

[5]. Sugiharto, Agus. 2002. Penerapan Dasar Transducer dan Sensor. Yogyakarta : Kanisius.

[6]. Sofwan A, dkk, 2005 Rancang Bangun Sistem Pengendali Suhu dan Kelembaban Udara pada Rumah wallet Berbasis Mikrokontroler AT89C51

[7]. Anonim, 2019 ${ }^{1}$. www.tokopedia.com diakses 16 Juni 2019.

[8]. Listiyarini, Ratih, 2018 Dasar Listrik dan Elektronika. Yogyakarta : Deepublish 